\title{
Estimating the Dog Population, Responsible Pet Ownership, and Intestinal Parasitism in Dogs in Quito, Ecuador
}

\section{Colon Jaime Grijalva ( $\nabla$ cgrijalva@asig.com.ec)}

Universidad San Francisco de Quito https://orcid.org/0000-0001-8492-5489

\section{Heather S. Walden}

University of Florida College of Veterinary Medicine

\section{P. Cynda Crawford}

University of Florida College of Veterinary Medicine

\section{Julie K. Levy}

University of Florida College of Veterinary Medicine

\section{William E. Pine}

University of Florida Department of Wildlife Ecology and Conservation

Jorge A. Hernandez

University of Florida College of Veterinary Medicine

\section{Research Article}

Keywords: Quito, dogs, dog population, responsible pet ownership, burden of intestinal parasites, canine ecology

Posted Date: May 24th, 2021

DOI: https://doi.org/10.21203/rs.3.rs-264981/v1

License: (c) (1) This work is licensed under a Creative Commons Attribution 4.0 International License. Read Full License 


\section{Abstract}

In 2011, authorities of Quito, the capital city of Ecuador, approved an ordinance to promote public health and animal welfare through responsible pet ownership promotion. The population of dogs was not known, and the relationships between dog abundance, socio-economic factors, prevalence of zoonotic gastrointestinal parasites, and pet ownership responsibility had not been investigated. The objectives of this study were (i) to estimate the human:dog (HD) ratio, (ii) to examine the relationship between household factors and responsible pet ownership and (iii) to estimate the prevalence of households with one or more dogs infected with intestinal parasites in Quito, Ecuador. Space-based random sampling procedures were used for estimation of HD ratios in stray dogs and confined owned dogs. The relationship between household factors and a responsible pet ownership index was examined using logistic regression. Dog fecal samples were tested for intestinal parasites. Among stray dogs, the observed HD ratio was 58:1. Among dogs kept indoors, the observed HD ratio was 3,5:1. A positive interaction effect between number of dogs in study households and household living conditions (a proxy for household wealth) on responsible pet ownership was observed, which we discuss in this report. Prevalence of households with dogs infected with intestinal parasites was $28 \%(95 \% \mathrm{Cl}=21-37)$. Ancylostoma spp. was the most frequent intestinal parasite in study dogs kept indoors. This study provides new information that can be used by policy makers to formulate, implement, and evaluate public policies and education programs aimed at enhancing pet ownership responsibility in Ecuador.

\section{Introduction}

Responsible pet ownership is a new practice that is becoming more common in the growing, mostly urban Ecuadoran middle class (Castellanos 2016; Universo 2017). However, dog overpopulation, lack of responsible pet ownership, and absence of animal shelter programs are continuing public health issues of concern in Quito, the capital city of Ecuador. In recent years, a number of organizations have advocated for improving pet welfare and in 2011, authorities in the city of Quito approved an ordinance to prevent cruel treatment of animals, promote responsible pet ownership, improve dog health, and reduce the risk of dog bites to people, dog defecation in public spaces, and stray and unwanted animals. In recent years, the number of organizations advocating for the implementation of policies that support responsible pet ownership has increased, as well as the demand for high quality high volume spay neuter (HQHVSN) clinics. A single agent type model utilized in Santa Cruz's (Santa Cruz Island, Galapagos, Ecuador) dog population recommend an annual spay-neutering between 300/3300 ( 12\%) to $500 / 3300(\sim 15 \%)$ of the total population of dogs via HQHVSN clinics to significantly reduce the population in 10 years (Diaz et al. 2018). Rural residence, low level of education, and low income have been identified as broad factors associated with a lack of responsible pet ownership including normal hygienic practices, responsible breeding, pet adequate nutrition, comfortable housing, mental health, and physical health (Ortega-Pacheco et al. 2007; Slater et al. 2008; Acosta-Jamett et al. 2010; Overgaauw et al. 2020)

To our knowledge, the population of dogs in Quito has not been investigated using objective research methods. In 2010 and 2013, Quito officials reported a human:dog (HD) ratio of 12:1 based on data extrapolated from published reports for capital cities in Latin America (Diario Hoy 2010; Jacome 2013). However, the absence of direct estimates for Quito makes it impossible to assess whether dog populations are responding as intended to government ordinances.

There are limited published studies related to prevalence of dog with gastrointestinal (GI) parasites in Ecuador and the Andean Region. These studies are useful to provide information on pet and human health conditions. A study in Santa Cruz, San Cristobal and Isabela analyzed the prevalence of intestinal parasitism using a convenience sample of 97 owned dogs that were presented to temporary HQHVSN clinics in Isabela, Santa Cruz and San Cristobal. Fecal samples were collected during a neutering process and processed using the Sheather Sugar flotation method. Morphological analysis was used to determine the presence of gastrointestinal parasites. In addition, a commercially available immunofluorescence assay for analysis of Cryptosporidium spp. and Giardia spp. was used. The prevalence of infected dogs for the whole sample population was 71,4 $\%$. The most commonly detected parasites were Ancylostoma caninum (57,7\%) and Toxocara canis (16,5\%) (Gingrich et al. 2010). Another study in Santa Cruz in 2014 used a randomly selected household sample. A total of 56 fecal samples processed using Sheather sugar flotation for morphological analysis stained samples for Cryptosporidium spp. Also, the 
samples were evaluated by a commercial ELISA for the presence of soluble antigen of Giardia spp. The most prevalent GI parasites in this study were Ancylostoma spp. (38\%), Toxocara spp. (5\%), and Cryptosporidium spp. (4\%). No dogs were positive to Giardia spp (Diaz et al. 2016).

Ancylostoma spp. is the most frequent parasite found in studies in the Andean Region (Ramirez-Barrios et al. 2004; Gingrich et al. 2010). The geographic distribution of this parasite is related to the temperature of the location and some species of Ancylostoma spp. are frequently found in places with a temperature higher than $20^{\circ} \mathrm{C}$. Only three species of Ancylostoma are considered zoonotic: A. ceylanicum, A. caninum and A brazilense. A. ceylanicum often successful infecting humans and $A$. caninum has zoonotic behavior occasionally. On the other hand, $A$. brazilense is mainly responsible for the "creeping eruption" or cutaneous larva migrans which is the percutaneous infection of L3 in humans. Human infections with Ancylostoma spp. are more common in children and adults that spend time barefoot in areas with warm and moist weather. Professionals with more risk are construction workers and gardeners since their job puts them in direct contact with dirt that could be contaminated with L3. The organ systems involved most commonly are skin, blood and intestine. The infection by skin of the infectious third-stage larvae of $A$. caninum or $A$. brazilense will cause skin lesions. Eosinophilic enteritis has been reported in infections with A. caninum. or A. ceylanicum. Infections occur mainly peroral and cause abdominal symptoms (Overgaauw and Van Knapen 2000; Bowman et al. 2010). Toxocara canis is probably the most common GI helminth that infects dogs worldwide. The reported infection rates in domestic dogs vary from 3,5\% in adults to $79 \%$ in puppies. The mode of transmission in humans is ingesting eggs from contaminated soil, hands and raw vegetables or by the consumption of undercooked meat of a paratenic host. Direct contact with infected dogs is not considered a transmission risk since the parasite ova requires a period of three weeks to embryonate and become infective. In humans, the literature reports that infections in children are more frequent. Severe visceral larva migrans is mainly found in children between 1-3 years of age. Geophagic pica is described as a major risk factor to be infected with $T$. canis. This behavioral disorder may affect a range of 2 to $10 \%$ of children between 1 and 6 years old (Overgaauw and Van Knapen 2000; Moreiral et al. 2014).

In 2012 Quito authorities requested assistance in estimating the dog population, baseline data on responsible pet ownership and the burden of dogs infected with intestinal parasites in the city of Quito. We present the results of an effort to address these questions by: (i) estimate the HD ratio, (ii) examine the relationship between household factors and responsible pet ownership and (iii) estimate the prevalence of households with one or more dogs infected with intestinal parasites in Quito, Ecuador.

\section{Materials And Methods}

\subsection{Study site}

This study was conducted in the Metropolitan District of Quito, the capital city of Ecuador, during June-August 2013. The estimated human population was about 2,3 million people residing in 634611 households (INEC 2011a). Quito is divided into 65 Parishes, of which 32 are located in urban areas and 33 in rural areas.

\subsection{Definitions}

Stray dogs were those (owned or not owned) observed stray by one of the authors (CJG) between 400 and 600 on twoconsecutive days during the study period (World Organisation for Animal Health 2019)

Confined owned dogs were those declared as owned by the household chief and kept indoors or inside household (property) limits at the time of the visit. Some dogs were allowed to roam free (with or without supervision) in public spaces to play or defecate during AM or PM hours.

A household is a housing unit composed by those living together under the same roof (e.g., home or apartment).

The household chief is the person who is in charge of the household at the moment of the data collection. 
Commercial food was defined as food manufactured for the purpose of feeding dogs produced by the industry that generally has a veterinarian specialist in nutrition behind the formulation.

Specially prepared food was defined as fresh food specially prepared by the dog owner for the dogs in the household.

\subsection{Sampling and counting of stray dogs}

A representative sample of parishes was selected from a map starting with one Parish roughly located in the center. Then each Parish was identified with one of four colors (avoiding to assign the same color to adjacent Parishes) (Figure 1) (WSPA 2008; Hossain et al. 2013). This approach identified three groups of 16 Parishes and one group of 17 Parishes (with one color for each group). Second, one of four colors was randomly selected to identify one group of study Parishes. Eight of 16 selected Parishes (Rumipamba, Mariscal Sucre, La Magdalena, La Ecuatoriana, Carcelén, San Isidro del Inca, Puengasí, Solanda) were located in urban areas and eight more (La Merced, Nanegalito, Chavezpamba, Yaruquí, Conocoto, Calderón, Calacalí, Nayón) in rural areas. Third, within each selected Parish, Sections were created using Google Earth ${ }^{\circledR}$. Each Section had a walking distance of approximately $5 \mathrm{~km}$ on public routes and was identified with a unique number. Each Parish had a median number of 25 Sections (Range: 3-90). Two Sections were then randomly selected where stray dogs were to be counted using random numbers from a computer algorithm (available at http://www.randomizer.org)

Counting of stray dogs was conducted by one author (CJG) on a total of 32 Sections (two selected Sections $\times 16$ Parishes $=32$ Sections). Each Section was walked at an average speed of $4 \mathrm{~km} / \mathrm{h}$ on two consecutive days (e.g., Monday and Tuesday) between 400 and 600 . A metropolitan police officer accompanied the surveyor for safety. This time period was selected because it is a reported period during which dogs search of food, defecate without dog owner supervision, and avoid morning car traffic (WSPA 2008). A tally counter was used to count dogs each day (e.g., "captured" dogs). An Earthmate § PN 60 GPS device was used to record the track followed the first day, and the same track was followed the second day. Dogs that were counted were registered on a digital photographic archive using a Canon® PowerShot D20 camera equipped with a GPS devise. The photographic archive and a second tally counter were used to identify dogs observed on both observation days (e.g., "re-captured" dogs).

\subsection{Sampling and counting of confined owned dogs}

Within each selected Parish $(n=16)$ and each selected Section $(n=32)$, all Blocks (approximately 14 Blocks per section) were considered for inclusion, but only one Block per Section was randomly selected and included in the study for a total of 64 blocks. All households in selected Blocks were visited for a personal interview with the household chief. Participation in the personal interview was voluntary, and only household chiefs who approved and signed a consent form were included in this study. Blocks in rural Parishes were not clearly defined. Thus, all households in the selected Section were targeted for inclusion in the study.

\subsection{Collection of fecal samples and diagnosis of intestinal parasites in confined owned dogs}

During house-to-house visits, each household chief was instructed to collect one fecal sample from at least one of her/his dog(s) from the ground, after normal defecation. On a first home visit (day 1), the household chief was provided with two pairs of gloves, a disposable tongue depressor and two sterile plastic specimen containers $(100 \mathrm{ml})$ labeled with the dog's name and date. Participant dog owners were instructed how to safely collect dog fecal samples. If canine fecal samples were visible in the home backyard, he/she was provided with zip-lock bags and instructed to safely collect a dog fecal sample from the ground by turning the bag inside out. All fecal samples were collected the following day (day 2) and submitted to a designated laboratory at the University of San Francisco de Quito for identification of intestinal parasites. The parasitological exam consisted in identification of morphological characteristics of parasite eggs, cysts and oocysts using a Sheather's sugar centrifugational flotation and sedimentation techniques (Diaz et al. 2016).

\subsection{Data collection}

Page $4 / 15$ 
Poverty rates (\%) published in Ecuador's National Population and Housing Census in 2010 were collected for each study parish. For each study household, the following data were collected: date of interview; Parish identification; residence (urban, rural); number of people in the household; number of dogs in the household; household with one or more dogs with a positive diagnosis of intestinal parasites (yes, no); responsible pet ownership index (score 1 to 8); and living condition index (score 1 to 9). Finally, for each study dog, the following data were collected: dog name, age, sex (male, female), spay neuter status (yes, no), free-roam (yes, no), dog is walked with a leash (yes, no), adequate shelter (yes, no), feeding (commercial food, specially prepared food, scrap food from human meals), dog visited veterinary office in the last 12 months (yes, no), dog was dewormed in the last 6 months (yes, no), and last time dog was vaccinated against rabies (months, don't know).

An instrument was prepared to measure a Responsible Pet Ownership Index (RPOI) in each study household (Table 1). The instrument included eight parameters (i) spayed/neuter status; (ii) use of leash; (iii) dog shelter conditions; (iv) food; (v) veterinary care; (vi) rabies vaccination compliance; (vii) deworming; and (viii) allowance to free roaming. Scores of 0 to 1 or 0 to 2 were assigned to each parameter for a maximum score of 8 in each household. An instrument was prepared to measure a Living Condition Index ( $\mathrm{LCl}$ ) as a proxy for wealth in each study household (Table 2). The instrument included two parameters: (i) accumulated wealth (PC, e-mail account, TV, cars) and (ii) education (elementary school, middle school, high school, university). Scores of 0 to 4 were assigned to parameter, except for number of cars, for a maximum score of 9.

\subsection{Data analysis}

\subsubsection{Free Roaming Dogs}

Within each selected Section, the proportion of observed stray dogs during the first and second observations (e.g., "recaptured" dogs) was calculated using data collected with the second tally counter and GPS camera (WSPA 2008; Dias et al. 2013). The Chapman modified Lincoln-Petersen equation (Equation 1; Krebs 1999) was used to estimate the number of dogs (Greenwood and Robinson 2006),

$$
N=\frac{(n 1+1)(n 2+1)}{(m 2+1)}-1
$$

where $\mathrm{n} 1$ is the number of dogs observed during the first day (captured dogs), $\mathrm{n} 2$ is the number of dogs observed the next day, $\mathrm{m} 2$ is the number of dogs observed during the first and second day (e.g., "recaptured" dogs) and $\mathrm{N}$ is the estimated number of animals in each section. The rationale for using this method for counting dogs is to estimate the proportion of "recaptured" dogs during the second count (m2/n2); the assumption is that this proportion is the same as that in the population at large $(\mathrm{n} 1 / \mathrm{N})$. Ninety-five percent confidence intervals $(\mathrm{Cl})$ were estimated by using the Poisson distribution because data were not normally distributed, and the number of recaptures was less than 50 in study Parishes (Krebs 1999). Confidence intervals using the two-sample method (Greenwood and Robinson 2006)were only determined for residence (urban, rural) and for the total count since only 4 of 32 study Sections had a required number of $\geq 8$ recaptured dogs.

To estimate number of dogs in each selected Parish, the estimated numbers of dogs on Sections 1 and 2 were averaged, then multiplied by the total number of Sections in each selected Parish. To calculate the HD ratio in each study Parish, the official human population was divided by the estimated dog population. The sampling fraction method was used to estimate the overall number of dogs by residence in studied Parishes (urban, rural) (WSPA 2008). Overall HD ratios by residence were calculated dividing the official human population by the estimated dog population. The overall dog population estimate in all sampled Parishes and the estimated HD ratio for Quito were calculated using the same method.

The relationship between the abundance of stray dogs (HD ratio) (rank data) and official poverty rates (rank data) in study Parishes $(n=16)$ was examined using simple linear regression.

\subsubsection{Confined owned dogs}


The observed HD ratio was calculated by dividing the total number of people by the total number of dogs in study households. The variables for number of dogs and number of people in study Parishes $(n=16)$ were normally distributed. Thus, simple linear regression was used to calculate a beta coefficient to produce an additional HD ratio (i.e., 1 divided by the beta coefficient) and $95 \% \mathrm{Cl}$ derived from the regression results.

The median time of last rabies vaccination and deworming was computed. Wilcoxon sign rank test was used to calculate $95 \% \mathrm{Cl}$. The frequency of dogs that were examined by a veterinarian within last year was determined.

The association between responsible pet ownership index (RPOI) and investigated household factors was examined by using unconditional logistic regression (Szklo and Nieto 2000; Diaz et al. 2016). Study households were assigned into one of two groups with a low (0 to 5) or high (6 to 8 ) RPOI scores-based on the median distribution.

\subsubsection{Prevalence of and identification of exposure factors associated with intestinal parasitism in confined owned dogs.}

Prevalence of households with $\geq 1$ dogs with a positive diagnosis of intestinal parasites was calculated as the number of households with a positive diagnosis divided by the total number of households with dogs sampled and tested. In addition, prevalence of dogs with a positive diagnosis of intestinal parasites was calculated as the number of dogs with a positive diagnosis divided by the total number of dogs sampled and tested; $95 \% \mathrm{Cl}$ were calculated for each prevalence estimate assuming normal distribution (Dean et al. 2013). Finally, the relationship between investigated household factors and households with one or more dogs classified as infected with intestinal parasites was examined using unconditional logistic regression.

\section{Results}

\subsection{Stray dogs}

The estimated number of free roaming dogs in the 32 study Sections was 726 ( $95 \% \mathrm{Cl}=653-822)$. Overall, the HD ratio was $58: 1(95 \% \mathrm{Cl}=52: 1-65: 1)$. The abundance of stray dogs was higher in rural Parishes ( $\mathrm{HD}$ ratio $=47: 1 ; 95 \% \mathrm{Cl}=39: 1-55: 1$ ) compared to urban Parishes (HD ratio $=73: 1 ; 95 \% \mathrm{Cl}=61: 1-84: 1)$ (Tables 3 and 4$)$. Using linear regression, the HD ratio was negatively associated with official poverty rates in study Parishes $\left(\beta=-0,77 ; r=0,77 ; R^{2}=0,59 ; p<0,01\right)$.

\subsection{Confined owned dogs}

Among the 32 selected Blocks, 232/998 (23\%) households voluntarily participated in this study. The proportions of surveyed households were significantly different in urban $(126 / 701$ or $18 \%)$ and rural neighborhoods $(106 / 297$ or $36 \%)(p<0,01)$. A total of 194/232 or $84 \%$ household chiefs reported having one or more dogs for a total of 318 dogs. The median age of dogs was 2 years (minimum $=6$ weeks, first quartile $=1$ year; third quartile $=4$ years, maximum $=16$ years). A total of 195 dogs $(61 \% ; 95 \% \mathrm{Cl}$ $=56-67)$ were male, and 44 dogs $(14 \% ; 95 \% \mathrm{Cl}=10-18)$ were classified as spayed or neutered. The proportion of neutered male dogs $(20 / 194$ or $10 \%$; $95 \% \mathrm{Cl}=7-15)$ was lower compared to female spayed dogs $(24 / 122$ or $20 \% ; 95 \% \mathrm{Cl}=14-28)(p=0,02)$. Furthermore, 71 dogs $(22 \% ; 95 \% \mathrm{Cl}=18-27)$ were reported as allowed to free roam in public spaces. The proportion of dogs allowed to roam in public places was higher in rural Parishes (36\%; 95\% Cl $=28-44)$, compared to urban Parishes $(11 \% ; 95 \% \mathrm{Cl}$ = 7-17). Dogs in rural parishes were 4,37 times more likely to roam in rural parishes compared to urban parishes (OR=4,37;95\% $\mathrm{Cl} 2.49-7.94 ; \mathrm{p}<0,01)$. The proportion of free roaming males was higher $(54 / 194$ or $28 \% ; 95 \% \mathrm{Cl}=22-35)$ compared to females $(17 / 124$ or $14 \% ; 95 \% \mathrm{Cl}=9-21)(p<0,01)$. The proportion of owned free roaming spayed females was higher $(6 / 20$ or $30 \%$; $95 \%$

$\mathrm{Cl}=15-52)$ than the proportion of owned free roaming males $(1 / 24$ or $4 \% ; 95 \% \mathrm{Cl}=1-20)(p=0,03)$. The observed abundance of confined owned dogs was similar in urban Parishes (HD ratio $=3,2: 1)$ and rural Parishes $(3,3: 1)$. The proportion of dogs that were examined by a veterinarian within the last year was $187 / 319$ or $58,62 \%(95 \% \mathrm{Cl} 53,15-63,89 \%$; $<<0,01)$. The median time from last deworming was 4 months (pseudo median 4,49;95\% $\mathrm{Cl}=3,99-4,99$ ). The median time from last rabies vaccination was 4 months (pseudo median 4,$5 ; 95 \% \mathrm{Cl}=4-5$ ).

Using linear regression, the estimated correlation between number of dogs and number of people in participant households ( $r$ ) 
was 0,94 , and the beta coefficient was $0,29(\mathrm{Cl}=0,23-0,34)(\mathrm{SE}=0,02)$. In addition, using an estimated $\mathrm{HD}$ ratio of 3,5:1 (i.e., 1 / beta coefficient) and a human population of 2239 191, the estimated population of confined owned dogs in Quito was 649 $365(95 \% \mathrm{Cl}=515$ 014-761 325).

\subsection{Household factors associated with Responsible Pet Ownership}

We found that the responsible pet ownership in a household was influenced by the residence type, number of dogs, and LCI were all significant $(p<0,01)$. The variable for $\mathrm{LCl}$ was associated $(p<0,01)$ with the variable for residence. Thus, the explanatory variables for number of dogs in a household and $\mathrm{LCl}$ were further examined.

We found that the combined effect of number of dogs in the household and LCl on RPOI, and the analysis revealed that households with $\geq 2$ dogs and low LCl were 16,71 times more likely to have a low RPOI, compared to households with 1 dog and high LCl $(\mathrm{OR}=16,71 ; 95 \% \mathrm{Cl}=5,90-47,37 ; p<0,01)$. This observed combined effect on low RPOI $(\mathrm{OR}=16,71)$ was higher than the expected combined effect based on adding $(O R=7,37)$, and multiplying $(O R=11,90)$ absolute independent excesses due to $\mathrm{LCl}(\mathrm{OR}=2,39)$ or $(\mathrm{OR}=4,98)$ number of dogs in the household (Table 5$)$

\subsection{Intestinal parasites in confined owned dogs}

A total of 110 of 194 (57\%) households with one or more dogs returned a dog fecal sample. Thirty-one of 110 or $28 \%$ (95\% Cl= 21-37) study households had one or more dogs classified as infected with one or more intestinal parasites. Using univariable logistic regression, the odds of household with dogs infected with intestinal parasites was two times higher in households with low RPOI scores, compared to households with high RPOI scores; however, this association was not significant (crude OR = $2,09 ; 95 \% \mathrm{Cl}=0,90-4,86 ; p=0,09)$. Other investigated household factors were not associated with a positive diagnosis of intestinal parasites $(p \geq 0,12)$.

At the dog level, 39 of 154 or $25 \%$ (95\% Cl = 19-33) dogs were infected with one or more intestinal parasites (Table 6). Ancylostoma spp. was the most frequent parasite diagnosed in dogs (18/154 or $12 \% ; 95 \% \mathrm{Cl}=7-17)$ followed by Toxocara canis $(11 / 154$ or $7 \% ; 95 \% \mathrm{Cl}=4-12)$. Finally, eight (5\%) dogs were diagnosed as infected with two intestinal parasites $(95 \% \mathrm{Cl}=$ 2 , 9). In urban households the prevalence of dogs with Ancylostoma spp. was $9 / 59$ or $15 \%(95 \% \mathrm{Cl}=8-27) \operatorname{similar}(\mathrm{p}=0,74)$ to rural households which was $9 / 51$ or $18 \%(95 \% \mathrm{Cl}=9-31)$.

\section{Discussion}

\subsection{Stray dogs}

Overall, the estimated HD ratio of stray dogs was 58:1 and the abundance of stray dogs was higher in rural Parishes, compared to urban Parishes. In addition, a higher abundance of dogs was associated with higher poverty rates in study Parishes. These findings are in agreement with previous observations that a higher abundance of stray dogs is associated with low- or middle-income neighborhoods in Baltimore, Maryland between 1970 and 1971 (Overgaauw and Van Knapen 2000). In another study conducted in rural households in Yucatan, Mexico, $77 \%$ of study households did not have adequate fences to prevent dogs from roaming (Beck 2002; Ortega-Pacheco et al. 2007). Although the variable for inadequate fences was not measured in this study, households with inadequate fences or no fences are commonly observed in rural Parishes in Quito. To our knowledge, no other published studies have estimated the abundance of stray dogs relative to the human population in Quito.

\subsection{Confined owned dogs}

Among 998 selected households, 232 or $23 \%$ were surveyed, and the proportion of surveyed households was different between urban (18\%) and rural (36\%) neighborhoods. The response rate was lower in this study than a survey on Santa Cruz Island, Galapagos in September 2014 (166/227 or 73\%) (Diaz et al. 2016). It is possible that this was due in part to the lack of government officials participating in the current survey. The prevalence of crime against people in Quito $(21,83 \%)$ is higher 
than in the Galapagos (7,06\%), consequently, residents may be more reluctant to open the door to a stranger in Quito (INEC 2011b)

Among 232 study households, the observed HD ratio was 3,5:1. The observed HD ratio in Quito is smaller than that reported by City Officials in Quito in 2010 and 2013 (12:1) (Wray 2011) and in previous studies in Guayaquil, Ecuador in 1986 (7:1) (Beran and Frith 1988), and Santa Cruz Island, Ecuador in 2014 (6,1:1) (Diaz et al. 2016)All the cited studies had differences in methodologies for data collection and statistical analysis. Between 2009 and 2011 in Quito, city officials estimated HD ratio based on rates reported in other Latin American capital cities similar to Quito. On the other hand, in Guayaquil, Beran and Frith surveyed 1938 homes in 394 randomly selected squares of the city. Another approach was used in Santa Cruz, Galapagos. Explanations for a lower population in Santa Cruz, Galapagos could include the effects of the dog importation prohibition or a higher prevalence of sterilized dogs (40\%) compared to Quito (14\%) (Asamblea Nacional de la Republica del Ecuador 2015; Diaz et al. 2016)

\subsection{Household factors associated with Responsible Pet Ownership}

We observed a positive interaction effect between $\geq 2$ dogs in study households and a low household living condition index on responsible pet ownership. This finding can be explained by education and economic factors at the household level, which can influence compliance for responsible pet ownership as expected by policy makers in Quito, veterinary organizations, and the World Society for the Protection of Animals. Families with a low level of education may not appreciate the dimension of potential health hazards and consequences caused by irresponsible pet ownership practices. Low-income families may not have the financial means or access to pet veterinary services. Finally, family budgets can be further compromised with a higher number of dogs on the household. In a similar study developed in Pelotas, Brazil, 1558 households were examined for responsible pet ownership. Using similar parameters to develop a score for responsible pet ownership they found an association between level of education of the household chief $(p<0,001)$ and low responsible pet ownership index (Domingues et al. 2015). To our knowledge, no other published studies have examined the relationship between socio-economic drivers and responsible pet ownership.

\subsection{Intestinal parasites in confined owned dogs}

At the dog level, $25 \%$ of dogs were infected with one or more intestinal parasite, with Ancylostoma spp., the most common parasite, identified in $12 \%$ A caninum is a parasite that causes cutaneous larva migrans by third stage larvae penetration and migration under the skin of humans; however, in contrast to canids, humans are dead-end hosts (Shalaby et al. 2010). The observed burden of Ancylostoma spp. in dogs in Quito, Ecuador during June-August 2013 was lower, compared to that in dogs on Santa Cruz Island, Galapagos, Ecuador in September 2014 (21/56 or 38\%; 95\% Cl = 25, 50\%) (Diaz et al. 2016). On Santa Cruz Island, the frequency of dogs infected with Ancylostoma spp. was higher in rural neighborhoods, compared to urban neighborhoods; one explanation offered by Diaz et al (2016) was that environmental conditions (greater exposure and longer survival in soil) are more favorable in rural than in urban neighborhoods in Santa Cruz Island. In this study the prevalence of Ancylostoma spp. was similar in urban households compared to rural households. An explanation for this can be that the samples were taken during the dry season of Quito. Also, there is no major difference on the weather and altitude between the studied sections with the exception of Nanegalito (INAMHI 2011). Ancylostoma spp. is often the most frequent parasite found in dog studies in the Andean Region countries with a prevalences of $24.5 \%$ in Maracaibo, Venezuela, $13.9 \%$ in Quindio, Colombia, 38\% in Santa Cruz and 57.7\% in Isabela, Galápagos (Ramirez-Barrios et al. 2004; Giraldo et al. 2005; Gingrich et al. 2010; Diaz et al. 2016).

\subsection{Study limitations}

This study had several limitations. First, counting of stray dogs was limited to two of a median of 25 sections per selected Parish during two consecutive days, in a narrow time frame between 400 and 600 . It is possible the inclusion of more study sections, additional days of dog counting (e.g., 10 consecutive days), or additional time frames could have produced a higher or lower HD ratio, with more precision. 
Second, among confined owned dogs, the number of surveyed households was $23 \%$. The response rate was higher in rural areas $(36 \%)$ compared to urban areas $(18 \%)$ with the consequent reduction of the expected sample size.

Third, the RPOI and LCl were estimated based on information provided by household chiefs. It is possible several households could have been misclassified as having a low or high Index value. Although in this study, a low RPOI was associated with a low $\mathrm{LCl}$, an indication that observation bias was not high.

Finally, the burden of dogs infected with intestinal parasites was based on one fecal sample collected during the study period.

\section{Conclusions}

This study provides new baseline dog population, preventive veterinary medicine practices and veterinary care access data that can be used to formulate, implement, and evaluate the impact of HQHVSN clinics for dogs in Quito, Ecuador. Although the total dog population and their parasite burden was lower than reported in other areas of Ecuador, $28 \%$ of households owned dogs with parasites of zoonotic significance. Study results support allocation of resources to further promote education programs that can support Responsible Pet Ownership principles (spay-neuter procedures, deworming, access to veterinary services at low cost), particularly in rural neighborhoods, and neighborhoods with high poverty rates.

\section{Declarations}

Funding.- This study was funded by the Secretary of Higher Education, Science, Technology and Innovation (SENESCYT) the University of Florida's Center for Latin American Studies and the Tinker Foundation

Conflict of interests.- The authors declare that they have no conflict of interest

Availability of data and material.- The datasets generated during and/or analyzed during the current study are available from the corresponding author on reasonable request.

Code Availability.-Statistix 9 was used for statistical analysis

Ethics approval.--This study was approved by the Universidad San Francisco de Quito's Bioethics Committee, the University of Florida's Institutional Animal Care and Use Committee, and the University of Florida's Institutional Review Board.

Consent to participate.- Informed consent was obtained from all individual participants included in the study. Consent for publication.- Not Applicable

Acknowledgments

The author (CJG) was funded by Ecuador's Secretary of Higher Education, Science, Technology and Innovation (SENESCYT), the University of Florida's College of Veterinary Medicine, the Center for Latin American Studies and the Tinker Foundation. The College of Veterinary Medicine at Universidad San Francisco de Quito allowed the use of laboratory space for processing of fecal samples and diagnosis of intestinal parasites in dogs. The City of Quito's Metropolitan Police Department provided assistance during the survey of stray dogs in study neighborhoods.

\section{References}

1. Acosta-Jamett G, Cleaveland S, Cunningham A, Bronsvoort B (2010) Demography of domestic dogs in rural and urban areas of the Coquimbo region of Chile and implications for disease transmission. Prev Vet Med 94:272-281

2. Asamblea Nacional de la Republica del Ecuador (2015) Ley Organica de Regimen Especial de la Provincia de Galapagos. Of. $N^{0} 52030$

3. Beck AM (2002) The Ecology of Stray Dogs. Purdue University Press, West Lafayette, Indiana

4. Beran GW, Frith M (1988) Domestic Animal Rabies Control: An Overview. Rev Infect Dis 10:S672-S677

Page 9/15 
5. Bowman DD, Montgomery SP, Zajac AM, et al (2010) Review: Hookworms of dogs and cats as agents of cutaneous larva migrans. Trends Parasitol 26:162-167. https://doi.org/10.1016/j.pt.2010.01.005

6. Castellanos G (2016) Adopciones y eutanasias, las dos caras del bienestar animal I El Comercio. In: El Comer. https://www.elcomercio.com/tendencias/adopciones-eutanasias-cifras-ecuador-animalescallejeros.html. Accessed 19 Sep 2019

7. Dean K, Soe M, Sullivan A (2013) OpenEpi: Open Source Epidemiologic Statistics for Public Health

8. Diario Hoy (2010) hoy.com.ec

9. Dias R, Guilloux A, Borba M, et al (2013) Size and spatial distribution of stray dog population in the University of São Paulo campus, Brazil. Prev Vet Med 110:263-273

10. Diaz NM, Mendez GS, Grijalva CJ, et al (2016) Dog overpopulation and burden of exposure to canine distemper virus and other pathogens on Santa Cruz Island, Galapagos. Prev Vet Med 123:128-137.

https://doi.org/10.1016/j.prevetmed.2015.11.016

11. Diaz NM, Walden HS, Yoak A, et al (2018) Dog overpopulation and diagnosis of intestinal parasites on Santa Cruz Island, Galapagos 2016. Prev Vet Med 157:99-104. https://doi.org/10.1016/j.prevetmed.2018.06.003

12. Domingues LR, Cesar JA, Fassa AG, Domingues MR (2015) Responsible pet animal guardianship in the urban area of the municipality of Pelotas in the state of Rio Grande do Sul, Brazil. Cien Saude Colet 20:185-192. https://doi.org/10.1590/1413-81232014201.19632013

13. Gingrich EN, Scorza A V, Clifford EL, et al (2010) Intestinal parasites of dogs on the Galapagos. Vet Parasitol 169:404-407 14. Giraldo MI, García NL, Castaño JC (2005) Prevalencia de helmintos intestinales en caninos del departamento del Quindío

15. Greenwood J, Robinson R (2006) Ecological census techniques: a handbook. Cambridge University Press., Cambridge, UK,

16. Hossain M, Ahmed K, Marma A, et al (2013) A survey of the dog population in rural Bangladesh. Prev Vet Med 111:134138

17. INAMHI (2011) Anuario Meteorológico. Anu. Meteorológico 2014

18. INEC (2011a) Resultados del Censo 2010 de Poblacion y Vivienda en el Ecuador: Fasciculo Provincial Pichincha. 2012:2010 population census results for the province of

19. INEC (2011b) Encuesta de Victimización y Percepción de Inseguridad 2011. Ecuador en Cifras 2018

20. Jacome E (2013) El Comercio.com

21. Krebs CJ (1999) Ecological methodology, 2nd ed. Benjamin/Cummings, Menlo Park, Calif

22. Moreiral G, Telmo PD, Mendonca M, et al (2014) Human toxocariasis: current advances in diagnostics, treatment, and interventions. Trends Parasitol 30:456-464. https://doi.org/10.1016/j.pt.2014.07.003

23. Ortega-Pacheco A, Rodriguez-Buenfil J, Bolio-Gonzalez M, et al (2007) A Survey of Dog Populations in Urban and Rural Areas of Yucatan, Mexico. Anthrozoos 20:261-274

24. Overgaauw P, Van Knapen F (2000) Dogs, zoonoses, and public health. CABI Pub, New York

25. Overgaauw PAM, Vinke CM, Hagen MAE van, Lipman LJA (2020) A One Health Perspective on the Human-Companion Animal Relationship with Emphasis on Zoonotic Aspects. Int J Environ Res Public Health 17:3789. https://doi.org/10.3390/ijerph17113789

26. Ramirez-Barrios RA, Barboza-Mena G, Munoz J, et al (2004) Prevalence of intestinal parasites in dogs under veterinary care in Maracaibo, Venezuela. Vet Parasitol 121:11-20. https://doi.org/10.1016/j.vetpar.2004.02.024

27. Shalaby HA, Abdel-Shafy S, Derbala AA (2010) The role of dogs in transmission of Ascaris lumbricoides for humans. Parasitol Res 106:1021-1026. https://doi.org/10.1007/s00436-010-1755-8

28. Slater MR, Di Nardo A, Pediconi O, et al (2008) Free-roaming dogs and cats in central Italy: Public perceptions of the problem. Prev Vet Med 84:27-47. https://doi.org/10.1016/J.PREVETMED.2007.10.002

29. Szklo M, Nieto FJ (2000) Defining and assessing heterogeneity of effects: interaction. In: Epidemiology: beyond basics. Aspen Publishers Inc, Gaithersburg Maryland 
30. Universo E (2017) En la joya crean escuela de tenencia responsable de mascotas

31. World Organisation for Animal Health (2019) Terrestrial Animal Health Code: Glossary. In: Terr. Anim. Heal. Code. https://www.oie.int/index.php?id=169\&L=0\&htmfile=glossaire.htm. Accessed 9 Feb 2021

32. Wray N (2011) Se aprueba Ordenanza sobre control de animales en Quito. 2018

33. WSPA (2008) Surveying roaming dog populations: guidelines on methodology. 2012

\section{Tables}

Table 1. Parameters included in the Responsible Pet Ownership Index

\begin{tabular}{|c|c|c|}
\hline \multicolumn{2}{|l|}{ Factor } & \multirow[t]{2}{*}{ Score } \\
\hline Spayed/Neuter & Free-roaming without supervision & \\
\hline Yes & No & 2 \\
\hline Yes & Yes & 1 \\
\hline No & No & 1 \\
\hline No & Yes & 0 \\
\hline \multicolumn{2}{|l|}{$\begin{array}{l}\text { Use of leash } \\
\text { No } \\
\text { Yes }\end{array}$} & $\begin{array}{l}0 \\
1\end{array}$ \\
\hline \multicolumn{2}{|c|}{$\begin{array}{l}\text { Dog housing (shelter) conditions } \\
\text { Non-appropriate }\end{array}$} & $\begin{array}{l}0 \\
1\end{array}$ \\
\hline \multicolumn{2}{|l|}{$\begin{array}{l}\text { Food } \\
\text { ftovers }\end{array}$} & $\begin{array}{l}0 \\
1\end{array}$ \\
\hline \multicolumn{2}{|c|}{$\begin{array}{l}\text { Dog(s) was taken to the veterinary clinic in last } 12 \text { months } \\
\text { No } \\
\text { Yes }\end{array}$} & $\begin{array}{l}0 \\
1\end{array}$ \\
\hline \multicolumn{2}{|c|}{$\begin{array}{l}\text { Rabies vaccination is current ( } 12 \text { months) } \\
\text { No } \\
\text { Yes }\end{array}$} & $\begin{array}{l}0 \\
1\end{array}$ \\
\hline \multicolumn{2}{|c|}{$\begin{array}{l}\text { Dog was dewormed in last } 6 \text { months } \\
\text { No } \\
\text { Yes }\end{array}$} & $\begin{array}{l}0 \\
1\end{array}$ \\
\hline \multicolumn{2}{|l|}{ Maximum score } & 8 \\
\hline
\end{tabular}

Table 2. Parameters included in the Living Conditions Index (LCl) 


\begin{tabular}{|lll|}
\hline Factor & Category & Score \\
Accumulated wealth & PC & 1 \\
& E-mail & 1 \\
& TV & 1 \\
& Car(s) & $\leq 2$ \\
& & \\
Education & Elementary & 1 \\
& Middle & 2 \\
& High school & 3 \\
Maximum score & University & 4 \\
\hline
\end{tabular}

Table 3: Estimated population of stray dogs in the metropolitan area of Quito 


\begin{tabular}{|c|c|c|c|c|c|c|c|c|c|c|c|c|c|}
\hline & \multicolumn{5}{|c|}{ Section 1} & \multicolumn{8}{|c|}{ Section 2} \\
\hline & $\mathrm{n} 1$ & $\mathrm{n} 2$ & $\mathrm{~m} 2$ & $\mathrm{~N}$ & $95 \% \mathrm{Cl}$ & $\mathrm{n} 1$ & $\mathrm{n} 2$ & $\mathrm{~m} 2$ & $\mathrm{~N}$ & $95 \% \mathrm{Cl}$ & $\begin{array}{l}\text { Mean } \\
\text { Dogs in } \\
\text { Sections } \\
1 \& 2\end{array}$ & $\begin{array}{l}\text { Estimated } \\
\text { Human } \\
\text { Population } \\
\text { in Section }\end{array}$ & $\begin{array}{l}\text { Estimated } \\
\text { Human: } \\
\text { Dog Ratio } \\
\text { in Parish }\end{array}$ \\
\hline \multicolumn{14}{|l|}{$\begin{array}{l}\text { Urban } \\
\text { S.I. Inca }\end{array}$} \\
\hline & 14 & 16 & 8 & 27 & $18-38$ & 11 & 8 & 1 & 53 & $40-68$ & 40 & 978 & $24: 1$ \\
\hline Ecuatoriana & 23 & 28 & 15 & 43 & $32-57$ & 30 & 27 & 15 & 53 & $40-68$ & 48 & 1833 & $38: 1$ \\
\hline Puengasí & 9 & 13 & 3 & 34 & $24-47$ & 14 & 12 & 4 & 38 & $26-51$ & 36 & 1456 & $40: 1$ \\
\hline Magdalena & 3 & 3 & 0 & 15 & ND & 16 & 18 & 7 & 39 & $28-52$ & 27 & 1893 & $70: 1$ \\
\hline Carcelén & 14 & 14 & 5 & 37 & $26-50$ & 1 & 0 & 0 & 1 & $1-8$ & 19 & 2113 & $113: 1$ \\
\hline Solanda & 7 & 7 & 1 & 31 & $21-44$ & 10 & 6 & 2 & 25 & $17-36$ & 28 & 4349 & $156: 1$ \\
\hline Rumipamba & 0 & 3 & 0 & 3 & ND & 0 & 1 & 0 & 1 & ND & 2 & 1739 & $869: 1$ \\
\hline Mariscal & 0 & 1 & 0 & 1 & ND & 0 & 1 & 0 & 1 & ND & 1 & 998 & $998: 1$ \\
\hline \multicolumn{14}{|l|}{$\begin{array}{l}\text { Rural } \\
\text { La Merced }\end{array}$} \\
\hline & 16 & 21 & 3 & 93 & $\begin{array}{l}76- \\
113\end{array}$ & 5 & 3 & 2 & 7 & $3-14$ & 50 & 271 & $5: 1$ \\
\hline Nanegalito & 6 & 3 & 3 & 6 & $3-13$ & 2 & 5 & 0 & 17 & ND & 12 & 112 & $10: 1$ \\
\hline Calacalí & 1 & 8 & 0 & 17 & ND & 2 & 0 & 0 & 2 & $1-7$ & 10 & 169 & $18: 1$ \\
\hline Nayón & 22 & 15 & 6 & 52 & $38-67$ & 10 & 18 & 6 & 29 & $19-41$ & 40 & 920 & $23: 1$ \\
\hline Chavezpamba & 8 & 8 & 4 & 15 & $8-24$ & 5 & 2 & 2 & 5 & $2-12$ & 10 & 267 & $26: 1$ \\
\hline Calderón & 25 & 27 & 13 & 51 & $38-69$ & 5 & 7 & 4 & 9 & $5-17$ & 30 & 1692 & $57: 1$ \\
\hline Yaruquí & 8 & 4 & 2 & 14 & $8-23$ & 6 & 8 & 5 & 10 & $5-18$ & 12 & 1050 & $89: 1$ \\
\hline Conocoto & 4 & 3 & 2 & 6 & $3-13$ & 4 & 9 & 2 & 16 & $10-25$ & 11 & 1052 & 99:1 \\
\hline
\end{tabular}

$\mathrm{n} 1=$ dogs observed in the first count (captured dogs).

$\mathrm{n} 2=$ dogs observed in the second count.

$\mathrm{m} 2=$ dogs observed in both counts (re-captured dogs).

$\mathrm{N}=[(\mathrm{n} 1+1)(\mathrm{n} 2+1) /(\mathrm{m} 2+1)]-1$. (Greenwood and Robinson, 2006).

Table 4: Overall Estimated population of stray dogs in the metropolitan area of Quito 


\begin{tabular}{|llllllll|}
\hline & $\mathrm{n} 1$ & $\mathrm{n} 2$ & $\mathrm{~m} 2$ & $\mathrm{~N}(95 \% \mathrm{Cl})$ & $\begin{array}{l}\text { Sampling Fraction } \\
\text { (Sampled sections/Total } \\
\text { Sections) }\end{array}$ & $\begin{array}{l}\text { Estimated Human: Dog } \\
\text { Ratio } \\
(\mathrm{E})\end{array}$ & $\begin{array}{l}\text { Human: Dog } \\
\text { Ratio } \\
95 \% \mathrm{Cl}\end{array}$ \\
\hline Urban & 152 & 157 & 61 & $\begin{array}{l}389((337- \\
466))\end{array}$ & $\begin{array}{l}16 / 211 \\
\text { D/C }\end{array}$ & $61: 1-84: 1$ \\
\hline Rural & 129 & 141 & 54 & $\begin{array}{l}335(288- \\
406)\end{array}$ & $16 / 286$ & $47: 1$ & $39: 1-55: 1$ \\
\hline Total & 281 & 298 & 115 & $\begin{array}{l}726(653- \\
822)\end{array}$ & $32 / 497$ & $58: 1$ & $52: 1-65: 1$ \\
\hline
\end{tabular}

Table 5. Observed and expected effects of number of dogs in household and Living Condition Index on households with low Responsible Pet Ownership Index

\begin{tabular}{|lllll|}
\hline Dogs in household & Living Condition Index & Odds ratio & $95 \% \mathrm{Cl}^{*}$ & $p$ \\
1 & High & 1.00 & Reference & NA \\
1 & Low & 2.39 & $1.00,5.74$ & 0.05 \\
$\geq 2$ & High & 4.98 & $2.09,11.87$ & $<0.01$ \\
$\geq 2$ & Low & 16.71 & $5.90,47.37$ & $<0.01$ \\
\hline
\end{tabular}

*95\% confidence interval

Table 6: Frequency of observed gastrointestinal parasites in confined owned dogs

\begin{tabular}{|ll|}
\hline Parasite & Frequency \\
\hline Ancylostoma spp. & 18 \\
\hline Toxocara canis & 11 \\
\hline Cystoisospora spp. & 1 \\
\hline Trichuris spp. & 1 \\
\hline Co-infections: & 8 \\
\hline
\end{tabular}

\section{Figures}




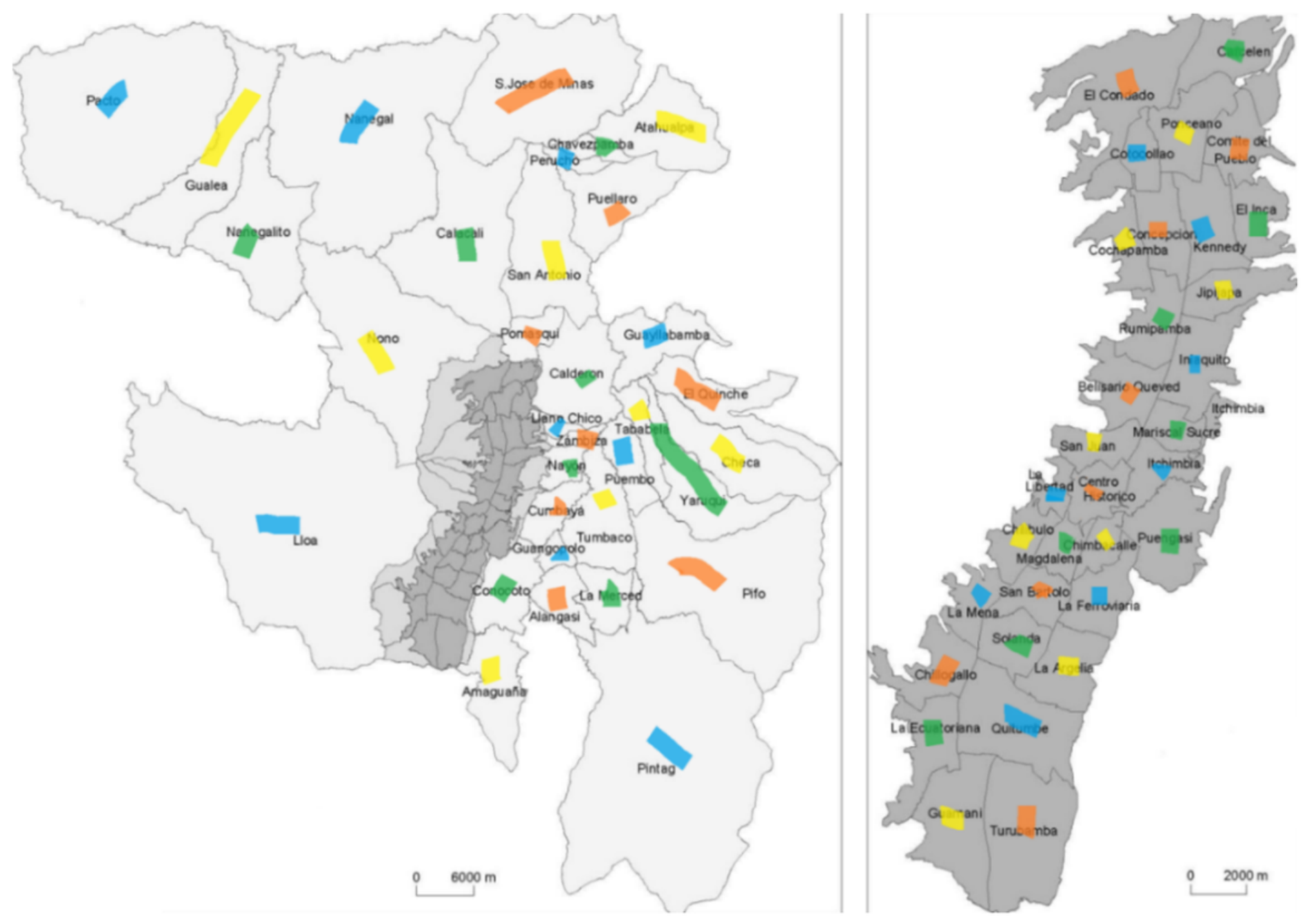

\section{Figure 1}

Geographic location of 65 parishes in the metropolitan area of Quito. Each parish was assigned to 1 of 4 colors (blue, yellow, green orange). Note: The designations employed and the presentation of the material on this map do not imply the expression of any opinion whatsoever on the part of Research Square concerning the legal status of any country, territory, city or area or of its authorities, or concerning the delimitation of its frontiers or boundaries. This map has been provided by the authors. 